\title{
Desafios para os Centros de Atenção Psicossocial como serviços substitutivos: a nova cronicidade em questão
}

\section{Challenges for Psychosocial Care Centers as alternative services: the new chronicity in question}

M ariana N ogueira Rangel Pande ${ }^{1}$

Paulo Duarte deCarvalho Amarante ${ }^{1}$

${ }^{1}$ Laboratório deEstudose Pesquisas em SaúdeM ental e Atenção Psicossocial, Escola Nacional de Saúde Pública Sergio Arouca, Fundação Oswaldo Cruz. Avenida Brasil 4036/506, Manguinhos. 21040-361 Rio deJaneiro RJ.

Abstract This paper is part of a qualitativelyoriented research project conducted in a Psychosocial Care Center (Caps) in Rio deJaneiro, Brazil. The goal of this work was to analyze the risks of a new chronicity in this service. The research was based on semi-structured interviews with professionals, patients and relatives, analyzing the data from a social constructionist perspective. The main conclusion of this study is that the people interviewed agreewith thetendency of a new chronicity, an expression that was useful to analyze the operations, advances and challenges of this service.

Key words Psychiatric reform, Disinstitutionalization, Psychosocial care, New chronicity
Resumo Este artigo advém de uma pesquisa exploratória, de base qualitativa, realizada em um Centro de Atenção Psicossocial (Caps) do Rio de Janeiro, com o objetivo de compreender a produção da nova cronicidade. Além da observação participante, foram realizadas entrevistas semiestruturadas com técnicos, usuários e familiares, tendo como base para análise dos dados a teoria do construcionismo social. Os resultados mostram que os entrevistados têm perspectivas que vão ao encontro da ideia de nova cronicidade, expressão que colaborou para uma análise do funcionamento, dos avanços e desafios encontrados nesse serviço. Palavras-chave Reforma psiquiátrica, Desinstitucionalização, A tenção psicossocial, N ova cronicidade 
Introdução

A preocupação com o tema da nova cronicidade no âmbito dos serviços de atenção psicossocial tem surgido recentemente, à medida que se evidenciam os grandes desafios na construção de serviços de fato inovadores ${ }^{1}$.

Tradicionalmente, a psiquiatria entende, grosso modo, que a "doença mental" (agora denominada de transtorno mental) tem caráter crônico, incurável, evoluindo naturalmentepara um quadro de degradação. Segundo essa perspectiva, os aspectos de degeneração da doença mental são inerentes a ela².

Já numa perspectiva crítica, autores como Barton ${ }^{3}$, Basaglia ${ }^{4}$ e Goffman ${ }^{5}$ acentuam o papel da institucionalização na produção da cronicidade, mais do que a suposta natureza da doença mental. Entendem queas instituições psiquiátricas tradicionais, baseadas na tutela, na hierarquia entre técnicos e pacientes, no afastamento dos internos em relação com a sociedade, entre outros aspectos, promovem um processo de cronificação dos pacientes.

Com os princípios da reforma psiquiátrica brasileira, supõe-se a superação do modelo asilar, subentendendo que a instauração de novos serviços, de portasabertas, debaseterritorial, com maior interlocução com a comunidade, proporcionaria um curso diferente daquele atribuído à suposta doença mental. No entanto, com o surgimento dos novos serviços, retornam a crítica à institucionalização e a reflexão sobre a nova cronicidade, assim como o entendimento de que tais serviços podem criar novas formas de institucionalização, cronificação ou até mesmo manicomialização ${ }^{6}$.

Em algumas cidades, a implantação de Centros de Atenção Psicossocial (Caps) tem como objetivo substituir o modelo hospitalar. Em outras, como é o caso do Rio de Janeiro, esses novos serviços passaram a compor a rede, coexistindo com os serviços já existentes, tais como ambulatórios e hospitais psiquiátricos.

Três autores apontam a existência da nova cronicidadevinculada aos novos serviços. Pepper et al. ${ }^{7}$ destacam mais a característica dos pacientes adultos jovens crônicos, perspectiva ligada ao entendimento tradicional de que parte da clientela dos serviços de saúde mental é crônica por sua natureza. Entendem que esses novos crônicosfazem uso recorrente, porém pouco resolutivo, dos serviços de saúde mental. Tais pacientes têm duas características comuns: dificuldade severa no funcionamento social e tendência a usar os serviçcos de saúde mental inapropriadamente, drenando tempo e energia dos clínicos, sem se adequar exatamente a um plano terapêutico. Para esses autores, os pacientes adultos jovens crônicos confundem nossos esforços em tratá-los de modo convencional, provocam distúrbios e evadem nossos programas de saúde mental, e apare cem de novo e de novo nas emergências psiquiátricas e delegacias de polícia?.

Desviat et al. ${ }^{8,9}$ destacam a insistência de pacientes crônicos nos novos serviços, apesar de todos os esforços na construção de estratégias territoriais. Para os autores, com o fechamento doshospícios, o otimismo quanto ao fim da cronicidade foi substituído pela evidência da persistência da cronicidade. Afirmam que a detecção [desse] grupo parecedesafiar o movimento desinstitucionalizador e tem servido como excelente argumento aos novos defensores do manicômio ${ }^{8}$.

Desviat ${ }^{9}$ defende a posição de que, a despeito da mudança na atenção à saúde mental, em que a cura foi substituída pelo cuidado, e em que maiores são os esforços em aumentar a autonomia e qualidade de vida dos pacientes, "é preciso aceitar a cronicidade e a limitação da eficácia re abilitadora" ${ }^{9}$. Desviat ${ }^{9}$ classifica quatro tipos de nova cronicidade:

1 - Remanescentes institucionais - são, de acordo com a literatura norte-americana, os tipo hard core, dificilmentedesinstitucionalizáveiseque retornam aos hospitais após tentativas de inserção nos novos serviços;

2 - Crônicos externalizados - são pacientes com longas internações em hospitais psiquiátricos que receberam alta devido à política de "redução de leitos";

3 - Usuários crônicos dos ambulatórios pacientes que chegam a ser crônicos sem nunca haver sido internados; são os eternos demandantes dos ambulatórios e dos centros psicossociais; não seguem tratamento regular porque não querem se deparar com seus conflitos internos e não sustentam a relação terapêutica;

4 - Pacientes adultos jovens crônicos (YACP, sigla em inglês) - termo cunhado por Pepper ${ }^{7}$, relativo a pacientes sem internações prolongadas, com comportamentos regredidos, quadros clínicos variados, dificuldade de adaptação social e uso "inapropriado" dos serviços, causando estresse aos profissionais. Caracterizam-se por agressividade, baixa tolerância à frustração, impulsividade e problemas com a lei. A presentam grande mobilidade quanto ao uso dos serviços fenômeno conhecido como porta-giratória ou revolving-door. Nos Estados Unidos, eles são 10\% dos pacientes psiquiátricos, ocupando cerca de 
$40 \%$ do tempo dos terapeutas. É comum que procurem excessivamente as emergências e que passem por numerosas internações ${ }^{8,10}$.

Já Rotelli et al. ${ }^{11}$ argumentam que a nova cronicidade está relacionada com as características do circuito psiquiátrico, quenão rompeu definitivamente com o paradigma tradicional. Os novos serviços adotam uma lógica empresarial, em que selecionam os pacientes de acordo com sua própria competência e recusam aqueles que não se encontram em seu perfil de atendimento nem estão adaptados às exigências do serviço. Tais autores utilizam a ideia do "circuito" para explicar que, ao contrário da instituição total, em que havia a estática da segregação, na psiquiatria reformada há a dinâmica "da circulação entre serviços especializados e prestações pontuais e fragmentadas" 11 , o que resulta em um número crescente de crônicos, um sentimento de impotência entre operadores e a necessidade de locais de internação como válvula de escape.

Assim, Rotelli et al. ${ }^{11}$ defendem a ideia deque a nova cronicidade é produto das práticas reformistas, que apostam na "liberação" do controle social exercido pela psiquiatria eprocuraram resgatar seu aspecto terapêutico. 0 resultado foi um sistema complexo que, somente reproduzindo a desospitalização, acaba por selecionar, decom- por, não se responsabilizar e abandonar. Assim, a nova cronicidade torna-se o sinal mais evidente da falência das intenções da psiquiatria reformada. Cada autor apresenta assim uma visão particular a respeito da noção de nova cronicidade, conforme sintetizado no Quadro 1.

Baseado no entendimento de "nova cronicidade" pelos autores estudados, procurou-se investigar a existência dessefenômeno em um Caps no município do Rio de Janeiro ${ }^{12}$, na perspectiva dos usuários, familiares e técnicos. Em outras palavras, o objetivo desta pesquisa foi extrair da fala dos entrevistados e da exploração do campo características do serviço e dos usuários que levassem a considerar a possibilidade de se reproduzir nos serviços de atenção psicossocial a chamada "nova cronicidade".

\section{Métodos}

0 presente artigo tem por base os dados advindos de uma pesquisa exploratória, fundamentalmente qualitativa, utilizando a estratégia de estudo de caso em um Caps situado no município do Rio de Janeiro.

Um estudo de caso comumente focaliza apenas uma unidade, como uma determinada insti-

Quadro 1. A nova cronicidade de acordo com Pepper et al. ${ }^{7}$, Desviat et al. ${ }^{8}$ e Rotelli et al. ${ }^{11}$.

\begin{tabular}{|c|c|c|c|}
\hline Autor & Expressão utilizada & Foco no problema & Características \\
\hline Pepper et al. ${ }^{7}$ & $\begin{array}{l}\text { Pacientes adultos } \\
\text { jovens crônicos. }\end{array}$ & No paciente. & $\begin{array}{l}\text { - Dificuldade no funcionamento social. } \\
\text { - Tendência a usar os serviços de saúde } \\
\text { mental inapropriadamente. } \\
\text { - Uso recorrente mas pouco resolutivo dos } \\
\text { serviços. } \\
\text { - Não adesão aos serviços. } \\
\text { - Comorbidade com drogas. } \\
\text { - Problemas com a lei. }\end{array}$ \\
\hline \multirow[t]{2}{*}{ Desviat et al. ${ }^{8}$} & \multirow[t]{2}{*}{ Nova cronicidade. } & Nos novos serviços. & $\begin{array}{l}\text { - Atuação "ritualizada" - conteúdo } \\
\text { estereotipado das entrevistas, frequências } \\
\text { inalteradas, neurolépticos prolongados. }\end{array}$ \\
\hline & & No paciente. & $\begin{array}{l}\text { - Remanescentes institucionais. } \\
\text { - Crônicos externalizados. } \\
\text { - Usuários crônicos dos ambulatórios. } \\
\text { - Pacientes adultos jovens crônicos. }\end{array}$ \\
\hline Rotelli et al. ${ }^{11}$ & Novos crônicos. & Na instituição. & $\begin{array}{l}\text { - Hiperespecialização. } \\
\text { - Refinamento das técnicas de intervenção. } \\
\text { - Circuito psiquiátrico. } \\
\text { - Resultado das práticas reformistas. }\end{array}$ \\
\hline
\end{tabular}


tuição. No estudo de caso instrumental, parte-se do princípio de que ele poderá ser útil para a compreensão de algo mais amplo, fornecendo insights sobre um determinado assunto. Ainda que não defina generalizações quantitativas, 0 estudo de caso pode gerar proposições teóricas aplicáveis a outros contextos. Além disso, o caso deve trazer algo de original, seja por sua natureza, seja por seu histórico, o contexto de que faz parte, outro caso pelo qual é conhecido, ou por seus informantes ${ }^{13}$.

No caso desta pesquisa, trata-se de um serviço considerado inovador no campo da assistência à saúde mental, sendo um dos primeiros criadosno Rio de Janeiro, servindo de modelo para outros que surgiram posteriormente. Quando da realização da pesquisa, o Caps tinha mais de dez anos de funcionamento. 0 critério utilizado para a escolha desse determinado Caps foi por se tratar de um dos mais antigos inaugurados nesse município, marcando uma trajetória que pode trazer contribuições para o tema.

A área programática (AP) onde se localiza abrange uma população de cerca de um milhão de habitantes. Durante a realização da pesquisa, essa área contava com mais um Caps, que se encontrava em fase de implantação e carecia de muitos profissionais. Nessa AP não havia hospitais psiquiátricos. Havia mais dois serviços com atendimento em saúde mental: um hospital geral e um centro municipal de saúde (CM S).

Esse Caps, assim como todos os outros do município do Rio de Janeiro, é classificado como Caps II. Isto significa que ele deveser responsável por atender à demanda de uma região com até 200 mil habitantes, e funciona das $8 \mathrm{~h}$ às $16 \mathrm{~h}$, de segunda a sexta-feira.

0 tempo de pesquisa em campo durou dois meses, tempo este suficiente para compreender, em linhas gerais, o funcionamento do serviço e colher os dados necessários para a pesquisa.

Como técnica para a produção de dados, foi realizada observação participante, incluindo as reuniões de equipe e as assembleias gerais, registradas no diário de campo. Além disso, realizaram-se entrevistas semiestruturadas com dez sujeitos - a coordenadora do serviço, três técnicos, três usuários etrês familiaresligadosao Caps, sendo as entrevistas gravadas e transcritas, baseadas em um roteiro previamente elaborado.

Foram selecionados os técnicos que participavam do serviço desde sua criação e que estavam diretamenteligados à assistência. Devido ao tempo de vinculação ao serviço, podiam ser considerados informantes privilegiados sobre a his- tória e as características do serviço. Também foram selecionados os usuários e familiares que estavam vinculados ao serviço por um período de ao menos cinco anos, caracterizando assim uma relação sólida com o serviço. Cabe destacar que os familiares selecionados não eram parentes dos mesmos usuários entrevistados.

Todos os usuários e familiares residiam na área de abrangência do serviço, em bairros do subúrbio do Rio de Janeiro, onde habita, grosso modo, uma população com baixo poder aquisitivo. Dos usuários entrevistados, dois eram do sexo masculino e um do sexo feminino. Apenas um deles já havia tido vida laborativa formal e todos haviam sido internados. Cada um deles ia ao serviço com frequências distintas. Dois participavam de oficinas e/ou trabalho de geração de renda. Um deles tinha partici pação menos regular, privilegiando atendimentos individuais com sua terapeuta.

Das familiares entrevistadas, duas delas eram mães dos usuários, ea outra, irmã. U ma das mães tinha participação ativa no serviço, frequentando o grupo de familiares e acompanhando o fiIho às atividades diárias. As outras duas só acompanhavam os usuários nas situações mais graves, ou em encontros casuais com as terapeutas.

Para a análise dos dados, foi utilizada a teoria do construcionismo social, através da análise das práticas discursivas e da produção de sentido no cotidiano ${ }^{14,15}$. As relações estabelecidas no campo do estudo foram interpretadas a partir de seus protagonistas, capazes de dar sentido e transformar a realidade. Essa metodologia parte da ideia de que o sujeito produz realidade ao falar, vendo-se implicado com o seu discurso. Enquanto os entrevistados explicitam o seu entendimento sobre o serviço, apresentam-se como atores em construção do processo, reproduzindo e/ou transformando a realidade.

Como instrumento de análise dos dados foi utilizado um mapa de associação de ideias, que se caracteriza por uma tabela com colunas temáticas que apontam os pontos principais do roteiro das entrevistas ${ }^{14}$. Elas permitem manter a sequência das falas ea contextualização do conteúdo. 0 mapa permite, em um segundo momento, redefinir as categorias de acordo com as entrevistas realizadas ${ }^{15}$.

Os temas que serviram como referência para a elaboração do roteiro de entrevistas estavam relacionados às características do serviço, como a forma de atendimento oferecida, a comparação com o hospital psiquiátrico e a sua relação com a comunidade, ou seja, indícios de como 
vinha se dando a construção de um serviço que se propunha verdadeiramente substitutivo.

Outras perguntas estavam ligadas à relação entre técnicos, usuários e familiares, como uma forma de compreender os novos tipos de vínculos formados nesse contexto. Abordou-se, por exemplo, a perspectiva de alta e as expectativas dos usuários em relação a isso, a participação dos diversos atores sociais no interior do serviço, o ideal de lugar de tratamento, o tempo de vinculação ao serviço e a expectativa de técnicos, familiares e usuários quanto ao tratamento e a vida desses últimos.

A bordou-se também a trajetória dos usuáriOS, a fim de se identificarem possíveis mudanças que tivessem ocorrido em suas biografias a partir da ligação com o Caps. Para isto, foram levantados como tema as atividades cotidianas e laborais dos usuários, seu histórico de internações psiquiátricas e o vínculo com outros serviços.

Finalmente, foi perguntado aos técnicos sobre suas perspectivas quanto à própria noção de "nova cronicidade", a fim de se identificarem debates e ideias que vinham se construindo sobreo tema no âmbito do serviço estudado.

A pesquisa na qual esteartigo se baseou levou em consideração os aspectos éticos necessários, tendo como base a Resolução n 196/96, ea aprovação da coordenação do serviço pesquisado, da Prefeitura do Rio deJaneiro edo Comitê de Ética em Pesquisa da Escola Nacional de Saúde Pública Sergio Arouca, da Fundação Oswaldo Cruz.

\section{Resultados ediscussão}

A partir dos dados advindos das observações nas reuniões de equipe e das entrevistas com os técnicos, foi possível identificar quadro grandes grupos de "casos clínicos", considerados exemplares no sentido de propor desafios para a equipe. Estas quatro categorias de usuários lançam luz à forma defuncionamento do serviço, assim como destacam temas que se mostram importantes para a equipe. Apesar de suas particularidades, cada grupo tem situações que se podem identificar com os chamados novos crônicos e/ou institucional izados e ocupam a equipe com os desafios que lançam, provocando questões quanto à sua vinculação ao serviço e exigindo mudanças constantes de estratégias.

Os usuários que ganham destaque na fala dos profissionais permitem uma boa análise da situação, uma vez que evidenciam as maiores contradições do serviço. Parte destas, usualmen- telatentes, revelam-senos momentosem quetais usuários representam desafios para os técnicos. $\mathrm{N}$ esses momentos são enfatizadas as relações hierárquicas, por meio das posições específicas ocupadas pelos técnicos e usuários. Além disso, torna-se mais evidente o caráter patológico através do qual a equipe os vê, o que serve para justificar as ações tidas como terapêuticas. Não há como evitar uma comparação dessa dinâmica com a interpretação psiquiátrica, entendida por Goffman ${ }^{5}$ como um olhar preconcebido, pautado em bases científicas, que justifica as ações de controle a partir das intervenções terapêuticas.

Relacionando os casos clínicos discutidos nas reuniões de equipe às concepções de nova cronicidade ${ }^{7-9,11}$, identificamos características dos usuários e do serviço que estão conectados com 0 conceito estudado.

0 primeiro tipo refere-se aos usuários parcialmente vinculados ao Caps, ainda em processo de avaliação no serviço; que têm uma demanda ambivalente, e parecem se aproveitar das contradições do serviço e manipular os técnicos a fim de obter "vantagens", como, por exemplo, medicação. É comum apresentarem comorbidade com o uso de drogas. São usuários que confundem a equipe e evidenciam as fal has do Caps. Circulam entre diferentes serviços, sem adesão a nenhum especificamente. A presentam-se pouco disponíveis a aproximações, tanto que durantea observação de campo não foi possível ter acesso a eles. São pacientes cujo comportamento se assemelha ao que Pepper et al. ${ }^{7}$ denominaram de pacientes adultos jovens crônicos. Para estes autores, tais pacientes fazem uso recorrente, porém pouco resolutivo, dos serviços de saúde mental. Eles têm como características a dificuldade severa no funcionamento social e a tendência a usar os serviços de saúde mental inapropriadamente, drenando tempo e energia dos clínicos, sem se adequar a um plano terapêutico.

0 segundo tipo refere-se aos usuários geralmente vinculados ao serviço há muito tempo e tidos como pacientes-problema. Assim como os primeiros, representam desafios para a equipe, colocam em xeque o funcionamento do serviço, evidenciam suas fal has e contradições. São presentes no cotidiano da instituição, polêmicos e afrontadores, desafiam oslimites entre pacientes e técnicos, provocam repetidas e exaustivas discussões pela equipe. Diante desses desafios, a tendência dos técnicos é de reforçar o caráter patológico de suas ações, entendendo que suas reivindicações são produto de sua doença mental. Ao mesmo tempo, tais usuários apresentam cer- 
to grau de dependência em relação ao serviço. Ainda que apresentem características de liderança, a maior parte deles restringe grande percentual de suas atividades cotidianas ao serviço, como suas refeições, atividades de geração de renda, oficinas terapêuticas etc. Na perspectiva dos técnicos, tais usuários parecem também estar de acordo com a noção de Pepper $^{7}$, porque trazem problemas ao serviço devido ao seu caráter patológico e por não apresentarem demandas claras e resolutivas. Apesar disso, não "circulam" pelos serviços como no tipo apresentado por Pepper, mas seu vínculo demasiado forte, quase dependente, aponta para o tipo que Desviat ${ }^{8}$ se referiu como os "usuários crônicos dos ambulatórios", tornando-se crônicos sem nunca terem sido internados.

Além desses, é comum a discussão sobreusuários provenientes de longas internações e que passam por um complexo processo de vinculação e adaptação ao Caps. Os usuários desse terceiro grupo exigem da equipe muitas negociações com seus familiares, com as equipes dos hospitais aos quais estão ligados, e a flexibilização de seus projetos terapêuticos. São usuários que refletem um processo visível de sequela decorrente da institucionalização e exigem estratégias complexas de intervenção. Eles parecem estar mais próximos da concepção de nova cronicidade segundo a perspectiva de Desviat ${ }^{9}$. Para este autor, o otimismo quanto ao fechamento dos hospícios foi substituído pela persistência da cronicidade, mesmo nos novos serviços. São, portanto, os "remanescentes institucionais" e desafiam qualquer possibilidade terapêutica.

Finalmente, ganha destaque um quarto grupo de usuários, que parecem "excessivamente" vinculados ao Caps, que dependem deseu funcionamento, chegando mesmo a se restringir àquele espaço. Participam de muitas oficinas, assembleias, fazem todas as refeições na unidade. $N$ ão apresentam problemas de adesão aos projetos terapêuticos oferecidos pelo serviço. Esses usuários são representantes da noção de nova cronicidade conformeapontada por Rotelli et al. ${ }^{11}$, para quem os novos crônicos surgem em número crescente devido à hiperespecialização e ao refinamento das técnicas de interven ção. Ou seja, com 0 avanço das formas de tratamento oferecidas pelos serviços territoriais, tais serviços podem muitas vezes se "especializar" em um determinado tipo de pacientes, ofertando-Ihes atividades no interior do próprio serviço que promovam a desospitalização, mas não necessariamente um processo complexo de desinstitucionalização da doença mental, mantendo uma lógica manicomial baseada na tutela e na dependência.

Muitos relatos dos entrevistados apontaram avanços importantes quanto à assistência prestada aos usuários no Caps, quando comparada com o tratamento do hospital psiquiátrico.

Observou-sea diminuição do tempo e da frequência das internações na maioria das falas, apontando para um serviço que prescinde gradativamente do recurso manicomial. Encontraram-se também, em muitos relatos, a boa qualidade dos serviços prestados no Caps, relações menos hierarquizadas entre os técnicos e os usuários efamiliares, entreoutras características que indicam transformação do modelo assistencial em relação ao tradicional.

No entanto, muitos entrevistados levantaram pontos importantes quelevam à ideia de que pode haver resquícios de institucional ização no serviço estudado. Os técnicos foram aqueles que se referiam mais claramente à noção de "cronicidade" e "nova cronicidade", não só por havermosfeito essa pergunta mais diretamente a eles como também por tal tema ter sido objeto de discussão anterior por parte dos técnicos no serviço estudado. Dessa forma, foram destacadas neste artigo mais referências claras à produção da "nova cronicidade" por parte dos técnicos. Por sua vez, os usuários e técnicos entrevistados também fizeram referências importantes a características da nova cronicidade, conforme encontrado na literatura revisada.

Durante as entrevistas, essa noção se destacou através do empobrecimento da vida dos usuários, da limitação de seus interesses e vínculos afetivos, da pouca mudança no seu cotidiano, 0 queéapresentado pelo usuário quefica "em casa", "deitado" e "fumando". Uma das técnicas associa a vida não produtiva às pessoas com histórico de internações, relacionando-a ao processo de cronificação decorrente do Caps.

$M$ as a característica destes pacientes é que não produzem lá fora. Ficam nesselugar mesmo do protegi do. É mais ou menos essa a característica mesmo de paciente com história de manicômio. Alguns pacientes mais antigos estão bem, mas estão em casa deitados, fumando. $M$ as a gente não vê 0 sujeito produtivo. Aí eu começo a achar queo Caps também é um instrumento que cronifica. (T3)

Dia a dia? Dormindo! Aí denoitenão dorme! Ele acorda, aí eu fico dando remédio a ele. Aí eleacorda, pronto, acabou. Aí perde o sono... fica vendo televisão. Eleéaposentado! Eletrabalhou lá na metalúrgica. Trabalhava lá, entendeu? Tanto queo patrão dele adora ele. Queera um rapaz responsável. Não faltava serviço, sempre tava ali, entendeu? (F2) 
Uma técnica evidencia um antagonismo pre sente nas discussões de equipe em que as mesmas características podem ser lidas tanto como produto da institucionalização quanto como resultado da doença mental, noção própria ao paradigma psiquiátrico tradicional.

Aquel eque tá sebeneficiando realmentedo serviço, buscando a sua cidadania, tá querendo participar de oficinas, e tem outro que não quer nada, quer vir aqui, dormir o dia inteiro [...] buscar remédio, almoçar, mas não tem interesse nenhum, um projeto de vida queelequei ra fazer. A equipe vê aqueles que "ah, ele não quer trabalhar porque é preguiçoso". O utros não: "é a doença mesmo, que não deixa ele fazer nada". (T2)

A noção de que a doença mental é incurável justifica o fato de que os usuáriosnão recebem alta do serviço. Algunsfamiliares acreditam queosusuários precisarão ser atendidos até o fim de suas vidas, tendo o Caps como referência. Para alguns técnicos não há possibilidade de cura, de modo que mesmo tendo sua frequência diminuída, eles têm sempre o risco da agudização de seu quadro.

Curado ele não vai ficar nunca mais. [...] e admitir que ele a vida toda vai precisar [do serviço]. (F1)

A noção dedependência apareceu nitidamente na fala dos entrevistados. Alguns trechos trazem a frequência diária dos usuários no serviço; outros, a concentração denumerosas atividades ali, inclusive as que poderiam ser realizadas em outros espaços.

[A gente faz] tudo aqui no Caps, [...] a gente vem todo mês. Segunda, terça, segunda, terça, quarta e sexta. E sábado e domingo a gente não vem, quinta a gente não vem. (U1 - a entrevista foi realizada numa quinta-feira)

Já uma entrevistada aponta que o momento em que os usuários entram no serviço favorece o início de um processo de dependência, uma vez que não se informa a possibilidade dequeum dia ele poderá ser encaminhado para outro serviço.

Tem usuário aí que fica num desespero, que não quer sair daqui, [...] ir pro ambulatório. [...] quando começou ninguém falou que as pessoas tinham um período pra ficar. Deveria ser assim: "Você vai ficar em avaliação por até seis meses. Se você melhorar, vai pro ambulatório." Aí o cara tá: "Ah, não, aqui ébom demais, tem almoço, tem café da manhã, tem o lanche..." Porquetudo éfeito aqui. [Os técnicos têm que] ir diminuindo o projeto dele. Q uetem usuário aí que não precisa ficar aqui 0 dia inteiro. (T2)

Uma familiar traduzo desejo do vínculo cotidiano de seu filho ao serviço, o que parece indi- car uma relação de dependência com o serviço, ao mesmo tempo que implica a restrição de outros vínculos externos. M esmo a vontade de que ele passeie deve se dar pelo intermédio do Caps. Ao mesmo tempo, refere-seao serviço como uma "clínica", apontando ainda para uma visão tradicional do serviço como lugar de tratamento.

Essa clínica aqui, quem dera! Que meu filho, que eu quero que ele venha aqui todo dia! Ele tava vindo de segunda a sexta aqui, entendeu? Que aí tem atividade, pra el efazer, entendeu?Tem passeio pra ele ir. (F2)

A longa duração apareceu de duas maneiras na fala dos entrevistados. Uma primeira relacionada ao tempo em que o usuário está vinculado ao serviço, que se estende indefinidamente, ao não receber alta; a outra relacionada à "espera", 0 Caps como lugar para "passar o tempo":

0 dia passa rapidinho quando vocêtá fazendo as coisa. Q uando você vê já passou, já é meio-dia, já éhora dealmoço, quando você vêjá é 3 horas, 4 horas, 5 horas. (U 3 )

...a própria terapeuta que me dava em cima: "Ah, faz um negocinho, faz um trabalhinho", negócio do interno aqui de dentro, "faz um trabalhinho, uma coisinha que te agrade, um passatempo, um exercício para passar o tempo". Eu nada! (U2)

Em todas as categorias de entrevistados, surgiu al guma referência aos usuários como "infantis". Em alguns casos, atribuiu-se à sua natureza; em outros, às relações entre técnicos e usuários e o tipo de tratamento que estes recebem. Em outros relatos, a "infantilização" não aparece explicitamente, mas através da compreensão do serviço como um lugar em que os usuários são protegidos. Um usuário sugere algumas atividades para o Caps, dentre elas a apresentação de desenhos animados, mais adequados para a clientela que frequenta o serviço.

U m filmequepassa no vídeo éuma coisa pesada, éuma coisa filmada, agora um desenho já bate mais com a infância. E alguns aqui são infantis ainda. U m desenho animado cairia bem, mais distrativo pra eles, né? Comunica mais com eles, né? A infância. (U2)

Partindo da perspectiva sociológica, Goffman $^{5}$ esquadrinha o estabelecimento psiquiátrico tradicional, dando visibilidade às mal has sutis que formam o comportamento do paciente. $N$ ão identifica a "infantilização" como decorrente de um processo patológico, mas como o produto da própria instituição.

Chama a atenção o fato de que o esforço do Caps para se aproximar da comunidade não apareceu como um projeto coletivo, mas como 
uma iniciativa particular de duas técnicas específicas, tidas como pessoas que têm o "perfil" da interlocução com a sociedade. Em outros momentos, a dificuldade na execução de atividades externas ao Caps aparece como uma falta de iniciativa do próprio usuário, que prefere se manter vinculado só ao Caps a usufruir de outros recursos oferecidos pela comunidade.

Com a comunidade a gente tem um trabalho da [técnica] que sai com eles por aqui. Então 0 pessoal da comunidade conhece. $M$ as ainda tem uma coisa cultural, ainda tem essa barreira. Isso pode ser um motivo também pelo qual eles prefiram às vezes estar dentro de casa do que enfrentar isso na rua. (T3)

Finalmente, em alguns momentos aparecem relações pautadas em diferenças hierárquicas, ainda que, em alguns discursos, aponte-se que técnicos eusuários têm uma relação de parceriae com poucas barreiras as separando.

Eu acho que é até legal [...] aquela coisa do profissional entre paciente, não existe tanto. É claro que às vezes atéaqui mesmo acaba muitas vezes sendo confundido. Já aconteceu do usuário ter tanta liberdade dessa relação queacaba não entendendo a presença dele aqui. Q uando a gente percebeu que [uma usuária] se sentia técnica! Exercia poder em cima dos outros usuários, sabe? Ela fazia o que ela achava [...], queria comparar poder: "Olha, eu estou aqui há muito tempo e você acabou de chegar, então...". Então a gente parou pra conversar e dizer: "Espera aí, não é assim. Ela aqui tem que entender que ela é paciente psiquiátrica." (T4)

Um usuário transmite a ideia, ainda presente no imaginário social, do portador de sofrimento mental como um alienado. Em seu discurso, isso justifica uma relação em queo técnico pode conduzir o usuário, o que vai contra o seu exercício de autonomia:

Por exemplo: você tá internando uma pessoa que não tem reflexo nenhum. Então pra que perguntar? Não tem mais pergunta. Você já sabe que ele tá conduzido, tem que conduzir mesmo, é isso. $\mathrm{N}$ ão raciocina direito. $\mathrm{N}$ ão tem faculdade, facultação, então pra que pergunta se é necessário pegar por ele? Então pega por ele, ele vai sem saber. [Rindo] Maluco não tem consciência. (U2)

Alvarenga e Dimenstein ${ }^{16}$ apontam que a desinstitucionalização é do social, do nosso apego às formas de vida institucionalizadas, onde é preciso [...] instigar a desconstrução cotidiana e interminável das relações de dominação. A lógica manicomial a ser desinstitucionalizada sustenta saberese práticas cronificadoras e de subjugação de uns pelos outros ${ }^{16}$.
Ostécnicos entrevistados encontram no Caps a possibilidade de produção da nova cronicidade, destacando sobretudo a capacidade do serviço em "manter" os usuários em seu interior. Entendem que isso se dá por proporcionar um espaço protegido, o que também implica sobrecarga edependência.

Você quando se fecha muito fica naquela coisa muito enrijecida, que fica muito trabalho. [...] A gente também reforçando, [o usuário] acaba ficando no Caps. 0 Caps éa única forma de vinculação, étudo: "Lá no Caps étudo na minha vida." [...] Quando você chega a restringir a tua vida a uma coisa só, é muita falta de opção! (T1)

Eles acreditam queo Caps pode produzir uma nova cronicidade, ainda que comporte características distintas dos pacientes institucionalizados dos hospícios. Entendem que a maior diferença são os ideais de cuidado, que, longe das práticas cruéis dos manicômios, conservam os usuários no serviço para protegê-los. Reconhecem uma crítica social ao potencial cronificador do Caps, reagindo com um misto de concordância e desagrado, uma vez que pontuam a qualidade do serviço ea intenção em oferecer atenção e cuidado.

Quando falam mini-hospício [...] eu não vejo isso, não. Porque ele não tem alta, o cara fica aqui dez anos. Então o cara já tá, né, crônico aqui dentro! M as é um crônico-light. M as não é uma cronificação ruim, perversa. Você vai cronificando porque você quer manter eleali, dando aquele cuidado. Tem muitas críticas [...] que o Caps tá cronificando. (T2)

Então é um hospício de porta aberta? 0 Caps cronifica, sim. É um outro modo, mas que cronifica de al guma forma esses pacientes. (T3)

Curioso o relato de uma técnica, para quem o usuário cronifica o serviço:

Essas pessoas que não são tão graves, vamos colocar entre aspas, poderia estar fazendo outras coisas e acabam cronificando o serviço. (T4)

Ainda que tocados pelos ideais da reforma psiquiátrica, as equipes dos serviços de saúde mental podem reproduzir a institucionalização e afirmar o manicômio, de modo que os desejos de manicômio ${ }^{16}$ atravessam o tecido social e estão presentes no cotidiano das práticas no campo da saúde mental.

\section{Considerações finais}

Verificou-se que persiste no imaginário dos entrevistados a concepção de que a clientela que 
frequenta o serviço é intrinsecamente crônica, noção esta retirada da psiquiatria tradicional e reeditada pela ideia de novos pacientes crônicos, conforme abordado por Pepper et al.?.

No entanto, em muitos momentos as entrevistas e a observação em campo apontaram para uma reflexão crítica dos técnicos a respeito de suas próprias práticas, reconhecendo-se como agentes que contribuem para uma relação de de pendência dos usuários em relação ao serviço.

Com todas as falas levantadas, tornam-se claras as relações que comportam perspectivas dicotômicas. Ora o Caps tem a preocupação em favorecer um intercâmbio com a comunidade, ora se reconhece fechado em si mesmo. Se por um lado exalta a cidadania dos usuários, por outro entende que deve protegêlos dos desafios impostos pela sociedade. Ao mesmo tempo que entende a necessidade de aproximação entre todos os seus membros, ressalta as diferenças e as mantêm intactas. As perspectivas opostas estão presentes, em um jogo de forças que compõe diferentes desenhos de acordo com a ocasião. Os serviços podem, a um só momento, cronificar, restringir, segregar, proteger, bem como libertar, favorecer autonomia, cidadania e protagonismo.
M esmo considerando as limitações desta pesquisa, que contou com número reduzido de sujeitos entrevistados em um único serviço, foi possível inferir a importância do objeto estudado. Os resultados indicaram que os mecanismos de institucionalização podem se dar mesmo em alguns serviços territoriais, ainda que estes tenham 0 objetivo de substituir o hospital psiquiátrico e, portanto, não reproduzir o modelo tradicional de atenção.

0 reconhecimento dos riscos da institucionalização por parte dos técnicos da assistência e de gestores éfundamental para que tais problemas possam ser minimizados. A consciência ea crítica a esses fatores é el emento de mudança necessário no processo de transformação do modelo de atenção à saúde mental.

Finalmente, a pesquisa indicou a importância de que o Caps deve utilizar, na medida do possível, estratégias e recursos existentes no território, procurando não se centrar exclusiva ou majoritariamente nas próprias atividades ou ações do serviço. I sso favorecerá o exercício da autonomia dos usuários, indo contra o risco da produção deuma nova cronicidadeou institucionalização.

\section{Colaboradores}

M NR PandeePDC Amaranteparticiparam igualmente de todas as etapas da elaboração do artigo. 


\section{Referências}

1. Amarante PDC, Torre EHG. A constituição de novas práticas no campo da atenção psicossocial: análise de dois projetos pioneiros na reforma psiquiátrica no Brasil. Saúde em Debate 2001; 25(58):26-34.

2. Kaplan HI, Sadock BJ, Grebb JA. Compêndio de psiquiatria: ciências do comportamento e psiquiatria clínica. Porto Alegre: Artes M édicas; 1997.

3. Barton R. Institutional neurosis. Bristol: John Wright \& Sons; 1966.

4. Basaglia F. A destruição do hospital psiquiátrico como lugar de institucionalização: mortificação e liberdade do "espaço fechado". In: Amarante P, organizador. Escritos selecionados em saúde mental e reforma psiquiátrica. Rio de Janeiro: Garamond; 2005. p. 23-34.

5. Goffman E. M anicômios, prisões e conventos. São Paulo: Perspectiva; 2003.

6. M ielke FB, Kantorski LP, Jardim VM R, Olschowsky A, Machado MS. O cuidado em saúde mental no Caps no entendimento dos profissionais. Cien Saude Colet 2009; 14(1):159-164.

7. Pepper B, Kirshner MC, Ryglewicz H. The young adult chronic patient: overview of a population (1981). Psychiatric Services 2000; 1(5):989-995.

8. Desviat M, Liria AF, OImedo GR. La nueva cronicidad. In: Espinosa JI, organizador. Cronicidad en psiquiatría. Madri: Asociacion Española de $\mathrm{Neu}$ ropsiquiatria; 1986. p. 305-358.

9. Desviat M. A reforma psiquiátrica. Rio de Janeiro: Editora Fiocruz; 1999. (Coleção Loucura \& Civilização).

10. Silva JPL. A desinstitucionalização e o processo de reformulação da assistência psiquiátrica no Rio de Janeiro no período 1995-2000: monitoração de resultados de uma política pública utilizando dados de inquérito epidemiológico associados a registros administrativos [dissertação]. Rio de Janeiro: Escola Nacional de Saúde Pública Sergio Arouca, Fundação Oswaldo Cruz; 2003.
11. Rotelli F, De Leonardis O, M auri D. Desinstitucionalização, uma outra via. In: Nicácio $F$, organizadora. Desinstitucionalização. São Paulo: Hucitec; 2001. p. 17-59.

12. Rangel, M N. A "nova" cronicidade nos "novos" serviços de atenção psicossocial [dissertação]. Rio de Janeiro: Escola Nacional de Saúde Pública Sergio Arouca, Fundação Oswaldo Cruz; 2008.

13. Alves-M azzotti A. U sos e abusos dos estudos de caso. Cad Pesq 2006; 129(36):637-651.

14. Spink MJP. Linguagem e produção de sentidos no cotidiano. Porto Alegre: EdiPUC-RS; 2004.

15. Spink MJP, Lima H. Rigor e visibilidade: a explicação dos passos da interpretação. In: Spink M JP, organizadora. Práticas discursivas e produção de sentidos no cotidiano: abordagens teóricas e metodológicas. São Paulo: Cortez; 2000. p. 93-122.

16. Alvarenga $A R$, Dimenstein $M$. A reforma psiquiátrica e os desafios da desinstitucionalização da loucura. Interface - Comunic, Saúde, Educ 2006; $10(20): 299-316$.

Artigo apresentado em 21/07/2009

Aprovado em 25/09/2009

Versão final apresentada em 12/11/2009 